\title{
Development of a Department Writing Guide for Civil Engineering
}

\author{
Mary U. Christiansen ${ }^{1}$, Eshan Dave ${ }^{1}$, Adrian T. Hanson ${ }^{2}$, Jill D. Jenson ${ }^{3}$, Sara Ojard ${ }^{4}$, David A. \\ Saftner ${ }^{1}$, and Rebecca Teasley ${ }^{1}$
}

${ }^{1}$ Assistant Professor, Dept. of Civil Engineering, University of Minnesota Duluth, Duluth, MN 55812; muchrist@d.umn.edu, evdave@d.umn.edu,dsaftner@d.umn.edu,\& rteasley@d.umn.edu ${ }^{2}$ Professor, Dept. of Civil Engineering, University of Minnesota Duluth, Duluth, MN 55812; athanson@d.umn.edu

${ }^{3}$ Associate Professor, Dept. of Writing Studies, University of Minnesota Duluth, Duluth, MN 55812; jjenson@d.umn.edu

${ }^{4}$ Adjunct Professor, Dept. of Civil Engineering, University of Minnesota Duluth, Duluth, MN 55812; sojard@d.umn.edu

\begin{abstract}
This paper describes the development of a writing guide for the University of Minnesota Duluth’s Department of Civil Engineering. Practicing engineers, academics, and accrediting agencies identify written communication as an essential component of an engineer's education. However, faculty experience in grading student work, conducting senior exit interviews, and completing the ABET assessment process, revealed shortcomings in student writing. Therefore, the authors began a project to develop a writing guide for use in all civil engineering courses. The writing guide covers reports, memos, figures, tables, equations, references, general homework submission requirements, and professional e-mails. The authors expect building faculty consensus, achieving an appropriate level of detail, and developing an assessment plan for use of the guide to be the most serious obstacles to its success. To overcome these obstacles, the authors are involving the entire department faculty, including tenured, tenure-track, and term faculty members, in developing and reviewing the project, so that consensus is reached and a common terminology is used. Prior to introducing the writing guide across the department's courses, student volunteers will use a draft to determine if the level of detail is appropriate. Finally, examples of student writing kept for previous ABET assessment and work from the Fall 2014 semester will be assessed to determine a pre-writing guide baseline. Future comparison between that analysis and assessment of post-writing guide student work will dictate whether the guide is helping to improve student writing as well as which sections of the writing guide require improvement.
\end{abstract}

\section{Introduction}

This paper describes how the civil engineering faculty members at the University of Minnesota Duluth (UMD) are working to improve the professionalism of written communication of undergraduate students through the developing and implementing a department-wide guide. For recently graduated engineers, proficiency in so-called "soft skills," such as communication and writing, often play second fiddle to "hard skills,” such as critical thinking, problem solving, and the need for up-to-date knowledge within the field. However, technical skills alone cannot make an engineer successful. Graduates must be able to efficiently and accurately communicate in writing. 
The department is newly ABET accredited and graduated its first class of undergraduate civil engineers in 2012. As a young program, the faculty places great emphasis on improving the program, with the goal of graduating well-rounded engineers capable of succeeding in the workplace. Data citing the need for improved writing instruction for upper-level civil engineering students came from many sources: 1) ABET evaluations, 2) student exit interviews with graduating seniors, and 3) faculty member's personal experience with students. The faculty unanimously agrees that writing skills are of the utmost importance to achieving the aforementioned objective and so has made improving the writing skills of all students graduating from the program a top priority. Consensus coupled with involvement of the UMD writing center faculty increase the writing guide's likelihood of success. Smith ${ }^{1}$ showed that collaboration between writing instructors and engineering faculty improves consistency within the writing curriculum throughout the program of study, provides a sense of teamwork, and validates the work done by each group.

This paper includes brief summary of the current writing curriculum at UMD as well as background information on the importance of writing in an engineering curriculum and suggestions for achievement put forth by other academics. Then the proposed structure of the writing guide will be discussed, along with perceived obstacles to its successful implementation. The authors hope this paper fosters conversations among faculty of other regional undergraduate engineering programs interested in improving the writing skills of their students.

\section{Background}

All students at the UMD take a required freshman-level writing course, followed by a juniorlevel writing course aimed toward engineering or technical writing. No other formal writing instruction is required aside from specific class assignments involving writing such as lab reports or project papers. The Civil Engineering Guide to Professional Written Communication, hereafter called the writing guide, is meant to supplement the more formal instruction provided by writing faculty.

In their high school and early college writing courses, students often work on "expressive writing” or self-directed writing. The switch from expressive to technical writing involves more than just a topic change, however; technical writing requires a specified structure, order, logic and clarity. ${ }^{2}$ Because technical writing initially proves to be difficult for most students, students at UMD will use the writing guide in all departmental classes. As is common across many engineering disciplines ${ }^{3}$, the first civil engineering course UMD students take is a freshman introductory class. Use of the writing guide early in the program will emphasize the importance of technical writing and prepare the students for the type of professional writing required of engineers.

Introducing the guide early will also help students understand the significance that writing and communication will have in their careers and increase their motivation to learn these skills. ${ }^{4}$ Bodmer et al. ${ }^{5}$ collected input from professors, engineers, and managers to show that communication skills, English language skills, teamwork abilities, and presentation skills ranked among the most important for new engineering hires. In addition, Jeffryes and Lafferty ${ }^{6}$ identified information seeking and learning proper citation skills as important for new engineers. 
Despite this, research shows a declining trend of student writing skills across all disciplines, due in part to exchanging essay-style tests for easier to grade multiple-choice or standardized tests, not focusing on writing quality in grading, and societal changes, such as incorporating technology and Internet use into daily life. ${ }^{3,7}$ Automated spelling and grammar correction and the endless store of information on the Internet seemingly removes the need for attention to writing and research skills. In many cases, students are no longer required to participate in tasks such as data gathering, creating an outline, or selecting references, because a simple Google search will often yield a ready-made template for their assignment. Social media also plays a role, where abbreviated words and emoticons take the place of sentences and complete thoughts. For these reasons and others, many students do not devote the time, energy, or thinking required for creating quality technical reports and documents.

Suggestions for how to improve writing skills include implementing intense freshmen-level writing courses aimed at developing strong habits early on, increasing the reading requirements in all classes, incorporating student peer reviewing, developing structured instructor feedback through grading rubrics, and rank-ordering students. ${ }^{7,8}$ Additionally, Bodmer et al. ${ }^{7}$ suggested altering the syllabus to include more, smaller writing tasks and assignments such as proposals, progress reports, and documentation of the writing and teamwork process, rather than just simply assigning a report. Requiring smaller, more frequent writing tasks offers more opportunities for faculty to instruct students on the writing process and provide feedback. For example, faculty at Southeast Missouri State University spent five years honing a similar discipline-specific system of writing instruction, referred to as the "System." It included a rubric followed by a "work order" that helped structure the writing, forcing students to identify what question each paragraph should address. The "System" increased students' abilities and reduced the time required to grade while still allowing for adequate feedback. ${ }^{9}$

Wheeler and McDonald ${ }^{10}$ showed that group work where students read their writing aloud and use the textbook was helpful in enhancing communication skills among students while not delving too deeply into classroom time meant for technical topics.

\section{Engineering Writing Guide Design}

The UMD Civil Engineering faculty envisions the writing guide incorporating many of these suggestions. Initial faculty meetings held in late 2013 and early 2014 focused on defining the content of the proposed department writing guide. As described above, the motivation for creating the writing guide came from consistent weaknesses in student work. Within laboratory, design, and research reports, students did not demonstrate the ability to consistently present professional figures, tables, equations, and references. Additionally, faculty members added two other topics addressing general professionalism: homework submissions and e-mail communication.

The report section of the writing guide is the largest. In order to accommodate research and design reports (which are generally submitted as part of senior-level electives and the required capstone design course) and laboratory reports (which are typically submitted in required juniorlevel classes), the writing guide defines a six-section outline for reports: summary, introduction, background, methods, discussion, and conclusion. The guide also acknowledges situations where one should delete sections or include extra sections. 
The memo, figure, table, equation, and reference sections are similar in that there are many accepted styles in practice. The writing guide presents one method for each of these topics as the department standard in addition to furnishing general rules consistent across all styles. For example, a memo header contains consistent information, regardless of the style of presentation. Further discussion of choosing one method from many acceptable methods follows in a subsequent section.

The homework submission and e-mail communication sections of the writing guide emphasize professionalism. The writing guide presents general recommendations on preparing homework submissions in addition to presenting examples of above and below average submissions. The writing guide addresses e-mail communication rather than general professional written communication because University required writing classes cover business letters and other traditional forms of written communication.

The final piece of the writing guide provides the skeleton of a grading rubric. While the specifics of an instructor's and/or assignment's rubric will differ greatly, the writing guide includes the general framework so students become familiar with the consistent standards faculty will use throughout the program. Students enrolled in the freshman level introductory civil engineering course will receive the writing guide and instructors will frequently use the document, introducing the evaluation process early in a student's educational experience. While the outlined grading rubric will not apply to any assignment in particular, familiarity with the expectations will increase student understanding of the evaluation process.

\section{Perceived Obstacles to Success}

The authors recognize that unforeseen issues will surface after implementation and for this reason the intent is for the writing guide be a living document. While future updates will address issues that arise through the document's use, the following section summarizes the main issues facing faculty and students in using of the first version of the writing guide, specifically consensus building, finding an appropriate level of detail, and developing an effective assessment plan.

\section{Consensus Building}

A primary concern in developing a department writing guide is ensuring that all instructors can effectively integrate the guide into their courses. If the guide becomes one faculty member's writing guide rather than a departmental writing guide, neither the authors nor the department will have accomplished their goal. Therefore, consensus building is an essential, ongoing part of the development process.

All faculty, including tenured, tenure-track and term members, approved of creating a document and agreed to provide feedback on drafts using the resulting guide in their courses. Recognizing varying schedule demands, faculty members participated in meetings and drafted sections of the guide when available. At least one faculty member other than the author reviewed each section of the writing guide prior to compiling the sections into a single document. Review of the first draft of the writing guide is ongoing, with expected completion before the end of the Fall 2014 semester. 
Another hindrance to consensus is a disagreement in terminology. For instance, the report section discusses technical objects and the outline of the grading rubric includes style and tone. Technical objects, style, and tone are examples of terms defined in the writing guide's glossary. The glossary prevents both student and faculty confusion about terminology and avoids multiple interpretations of the guide.

\section{Level of Detail}

The level of detail provided in the writing guide introduces potential pitfalls from both the student and faculty perspective. From the student's point of view, the guide must contain enough detail to ensure that expectations are understood. Without sufficient detail, the writing guide could result in an more confusing situation than the status quo in which individual instructors explain their own expectations. To ensure an adequate level of detail, student volunteers in a given course will use an initial draft of the writing guide the semester before it is implemented across the department. Faculty will use feedback from the volunteers to determine if the level of detail is appropriate and make any necessary changes before broad implementation.

Some faculty members have expressed concern that the writing guide will constrain their ability to emphasize certain points. For example, some faculty currently ask students to write step-bystep laboratory procedures in laboratory reports while others prefer students to refer to laboratory manuals or ASTM standards. In this example, the key difference is the audience and not the structure of the report. Consequently, the writing guide must reflect the importance of the audience and not allow the students to believe that a given template is acceptable in every circumstance, whether in school or in a professional situation.

\section{Assessment Plan}

Lastly, an effective assessment plan is essential to ensure that the writing guide improves the educational experience. As part of the department's assessment process, each instructor maintains copies of specific assignments from several previous semesters. Faculty members are currently evaluating those assignments using the newly developed grading rubric adapted for the specific assignment. A broader collection of assignments will be evaluated in the current semester. The resulting database will comprise the pre-writing guide baseline. In the semesters following implementation of the writing guide, currently planned for Spring 2015 semester, student writing will be assessed in a consistent manner and compared to pre-implementation results. This analysis will provide guidance on future revisions to the writing guide and its effectiveness.

Finally, it is important to emphasize the involvement of the UMD writing center. The writing center's mission is to help writers develop strategies that lead to better writing. It is available to all students and employees and offers one-on-one consultation led by faculty members and qualified graduate students. Involving an author from the writing center bring expertise in teaching writing not possessed by civil engineering faculty. Additionally, the faculty in the writing center teach University required upper-division writing classes. Their input in the civil engineering writing guide ensures consistency with the content presented in those courses. 


\section{Conclusion}

With the main goal of graduating high quality engineers in mind, the civil engineering department at UMD finds it crucial to increase the level of writing skills. Through implementing the writing guide, students will be told upfront what is expected from them and will have examples that help teach them the skills and lessons necessary to communicate their thoughts and ideas accurately and efficiently. The writing guide includes sections on reports, memos, figures, tables, equations, references, general homework submission requirements, and professional e-mails. Perceived obstacles to success are building consensus, finding an appropriate level of detail, and developing an assessment plan. The authors plan to assuage the risk of these potential obstacles by involving all department faculty, clearly defining the terminology used, seeking student feedback prior to introducing the writing guide in classes, and involving writing faculty with assessment experience.

\section{Acknowledgements}

The authors wish to thank the UMD writing center for their willingness to be involved from the conception of this project, expertise, and excitement throughout the writing guide's development. This support and assistance is gratefully acknowledged.

\section{Bibliography}

${ }^{1}$ Smith, S. (2003). "What is "Good" Technical Communication? A Comparison of the Standards of Writing and Engineering Instructors." Technical Communication Quarterly 12(1): 7-24.

${ }^{2}$ Warnock, S. and M. Kahn (2007). "Expressive/Exploratory Technical Writing (XTW) in Engineering: Shifting the Technical Writing Curriculum." Journal of Technical Writing and Communication 37(1): 37-57.

${ }^{3}$ Kalkani, E. C. and L. G. Boussiakou (2003). "Observations on an introductory engineering course and suggestions for enhancement." European Journal of Engineering Education 28(3): 317-329.

${ }^{4}$ Idrus, H., A. M. Noor and M. N. R. Baharom (2012). "Motivating Engineering and Technical Students to Learn Technical Writing by Inculcating Lifelong Learning Skills." The International Journal of Learning 18(11).

${ }^{5}$ Bodmer, C., A. Leu, L. Mira and H. Rutter (2002). SPINE: Successful practices in international engineering education: 102.

${ }^{6}$ Jeffryes, J. and M. Lafferty (2012). "Gauging Workplace Readiness: Assessing the Information Needs of Engineering Co-op Students." Issues in Science and Technology Librarianship.

${ }^{7}$ Carter, M. and H. Harper (2013). "Student Writing: Strategies to Reverse Ongoing Decline." Academic Questions 26(3): 285-295.

${ }^{8}$ Robinson, C. M. and G. M. Blair (1995). "Writing skills training for engineering students in large classes." Higher Education 30: 99-114.

${ }^{9}$ Boyd, G. and M. F. Hassett (2000). "Developing Critical Writing Skills in Engineering and Technology Students." Journal of Engineering Education: 409-412.

${ }^{10}$ Wheeler, E. and R. L. McDonald (2000). "Writing in Engineering Courses." Journal of Engineering Education 89(4): 481-486. 